\title{
Assessing European primary school performance through a conditional nonparametric model
}

\author{
José Manuel Cordero $^{1 *}$, Daniel Santín ${ }^{2}$ and Rosa Simancas ${ }^{1}$ \\ ${ }^{1}$ University of Extremadura, Badajoz, Spain; and ${ }^{2}$ Complutense University of Madrid, Madrid, Spain
}

This paper uses a fully nonparametric framework to assess the efficiency of primary schools using data about schools in 16 European countries participating in PIRLS 2011. This study represents an original enterprise since most of the empirical research in the field is restricted to evaluations at regional or national level and focused on secondary education. For our purpose, we adapt the metafrontier framework to compare and decompose the technical efficiency of primary schools operating in heterogeneous contexts, which in our case is represented by different educational systems or countries. Similarly, we use an extension of the conditional nonparametric robust approach to test the potential influence of a mixed set of environmental school factors and variables representing cultural values of each country. Our results indicate that the intergenerational transmission of non-cognitive skills such as responsibility or perseverance are significantly related to school efficiency, whereas most school factors do not seem to have a significant influence on school performance.

Journal of the Operational Research Society advance online publication, 24 June 2015; doi:10.1057/jors.2015.42

Keywords: education; cross-country analysis; nonparametric; conditional efficiency

\section{Introduction}

All countries are interested in improving the level of education of their citizens because it is considered as one of the main sources of human development (Krueger and Lindahl, 2001) as well as an important source of economic growth (Hanushek and Kimko, 2000; Barro, 2001; Hanushek and Woessmann, 2008). This evidence can explain why so many studies have attempted to explore the potential determinants of education using an educational production function (Hanushek, 1979), in which the quality of education is usually measured by test scores. In this sense, the participation of the majority of nations on common international large-scale assessments like PISA (Programme for International Student Assessment), TIMSS (Trends in International Mathematics and Science Study) or PIRLS (Progress in International Reading Literacy Study) has provided researchers with rich and extensive cross-national databases that can be used to assess the performance of educational systems from a comparative perspective. As a result, we can find an extensive literature using the entire world as a laboratory to explore the underlying determinants of educational achievement (Bray and Thomas, 1995; Hanushek and Woessman, 2011) or to analyse specific aspects such as the differences between public and private schools (Vandenberghe and Robin, 2004; Dronkers and Roberts, 2008), the effects of tracking (Brunello and Checchi, 2007; Schuetz et al, 2008) or the influence of accountability

\footnotetext{
*Correspondence: José Manuel Cordero, Departamento de Economía Universidad de Extremadura, Av. Elvas s/n, Badajoz 06071, Spain. E-mail: jmcordero@unex.es
}

(Bishop, 1997; Fuchs and Woessmann, 2007) to cite only some examples.

Since their main focus is the identification of significant relationships between educational outcomes and students and school-related variables, most of those cross-national studies apply econometric techniques. More recently, some of them have started to apply more sophisticated methods in order to identify causal relationships in the international data on educational achievement (see Hanushek and Woessmann, 2014 or Strietholt et al, 2014 for a review), although they do not consider the potential existence of an unexpected level of inefficiency in the performance of schools (Levin, 1974). In this sense, the actual constraints of resources faced by most of countries and the great amount of national income devoted to education expenditures have led policy makers and researchers to become increasingly concerned with assessing the efficiency of schools. However, most of these efficiency evaluations have been restricted to schools operating in the same country or region (see Grosskopf et al, 2014 for a recent review of this literature).

To the best of our knowledge, only few studies have applied frontier methods to micro data from those international data sets to evaluate the performance of educational systems using a cross-country approach. These include De Jorge and Santín (2010) and Deutsch et al (2013), which use PISA data at student level to estimate the efficiency of EU and Latin America countries respectively, while Wilson (2005) use PISA data at school level to assess the performance of 40 countries around the world. Moreover, we can find some empirical works using 
data aggregated at country level from different samples of countries participating in PISA (Afonso and St Aubyn, 2006; Giambona et al, 2011; Thieme et al, 2012; Aristovnik and Obadić, 2014) or TIMSS (Giménez et al, 2007). Those studies use predominantly the nonparametric data envelopment analysis to obtain efficiency measures of performance. (Deutsch et al, 2013, use corrected least squares.) Only in some cases, a twostage procedure is also applied to examine the potential influence of contextual variables on efficiency estimates (eg Afonso and St Aubyn, 2006; Verhoeven et al, 2007), but none of them incorporate this information into the estimation of efficiency scores.

In this paper we attempt to extend this scarce body of literature on cross-country efficiency analysis in the education sector by performing an assessment of primary schools operating in 16 European countries. For that purpose, we apply some recently developed nonparametric methods that allow us to overcome some of the main limitations of previous studies. Similarly, we incorporate into the analysis some additional data about contextual factors in each nation that can be extremely helpful to shed light on the divergences in performance across countries.

Our aim consists of applying some of the most recently developed methods in the literature of efficiency analysis to estimate measures of school performance in an international context. In particular, we use the robust order- $m$ methodology described by Cazals et al (2002) to avoid some of the main drawbacks of nonparametric methods. This approach consists of constructing a partial frontier using only part of the sample ( $m$ observations) to determine efficiency score; thus, the impact of potential outliers in data is reduced. Subsequently, we adapt the metafrontier framework developed by Battese and Rao (2002), Battese et al (2004) and O'Donnell et al (2008) to decompose the estimated inefficiency between two different levels (school and country). Finally, we use the conditional nonparametric approach proposed by Dario and Simar (2005, $2007 \mathrm{a}, \mathrm{b}$ ) to incorporate the effect of environmental factors into the estimation of efficiency scores and explore their potential influence without assuming the typical restrictive separability condition of two-stage approaches.

Some of those methodologies have been previously applied in empirical studies with educational data for specific countries. For example, De Witte et al (2010) used the order- $m$ approach to assess the performance of a sample of British secondary school pupils and Thieme et al (2013) combined this approach with a metafrontier approach to evaluate students in primary education in Chile. Similarly, the conditional approach has also been applied to evaluate public and private schools in Flanders (Cherchye et al, 2010), to evaluate the performance of teachers in Belgium (De Witte and Rogge, 2011), to analyse the impact of innovations on school performance in the Netherlands (Haelermans and De Witte, 2012) or to assess the performance of Dutch students (De Witte and Kortelainen, 2013). However, this paper represents the first combined application of those methods in a cross-country analysis using educational data from an international large-scale survey.
In particular, data used in our empirical analysis was retrieved from PIRLS 2011. This project, conducted by the International Association for the Evaluation of Educational Achievement (IEA), comprises data about students' reading achievement after four years of primary schooling. One of the main advantage of using this data set comes from the fact that most students have only attended one school, thus the effect of school is direct; while in studies based on PISA data students have usually studied in different centres (schools and high schools), thus part of the school effect is not captured by observed school variables since learning is a cumulative process. Moreover, the comparison among students in different educational systems is reasonably homogenous, since their results are not affected by tracking, which is not applied before the children are 10 years old in any country (see Brunello and Checchi, 2007, for details).

One of the main shortcomings of studies based on data from international large-scale assessments is their inability to understand the economic, cultural and social context of each country (Zhao et al, 2008; Täht and Must, 2013). In order to overcome this limitation we retrieved some additional information about economic indicators from the World Bank's Indicators database and collected data from some questions included in the World Values Survey (WVS) to approximate the cultural heritage of each country. Coco and Lagravinese (2014) also use this source of data to incorporate a proxy measure of hard work in their evaluation of education performance of OECD countries using PISA data. In our case, these variables are considered as potential factors that might affect the performance of schools operating in the same country when they are compared with schools in other countries.

The remainder of the paper is structured as follows. The next section describes the methodology. The subsequent section explains the main characteristics of the data and the variables selected for the empirical analysis. The penultimate section presents the main results and relates them to the existing literature. Finally, the paper ends with some concluding remarks in the final section.

\section{Methodology}

\section{The robust FDH model}

The definition of the production technology in the educational sector is a very difficult task. The only thing that we know is that pupils attending schools transform a set of heterogeneous inputs $x,\left(x \in \mathfrak{R}_{+}^{p}\right)$, including their own abilities, school variables and parental background (Hanushek et al, 2013), into heterogeneous outputs $y\left(y \in \mathfrak{R}_{+}^{q}\right)$, usually represented by test scores in a standardized assessment. The production technology is the set of all feasible input-output combinations:

$$
\psi=\left\{(x, y) \in \Re_{+}^{p+q} \mid x \text { can produce } y\right\}
$$

In order to estimate the relative efficiency of each school, we estimate a frontier that represents the best practice observations 
following the main ideas developed in the seminal work of Farrell (1957). In particular, our model is based on the nonparametric Free Disposal Hull (FDH) methodology (Deprins et al, 1984). The output-oriented efficiency score $\left(\hat{\lambda}_{\mathrm{FDH}}\right)$ of an observation can be obtained by solving the linear programming problem in Equation (2):

$$
\begin{gathered}
\hat{\lambda}_{\mathrm{FDH}}=\max \left\{\lambda \mid \lambda y \leqslant \sum_{i=1}^{N} \gamma_{i} y_{i} ; x \geqslant \sum_{i=1}^{N} \gamma_{i} x_{i} ; \sum_{i=1}^{N} \gamma_{i}=1 ;\right. \\
\left.\gamma_{i} \in\{0,1\} ; i=1, \ldots, n\right\}
\end{gathered}
$$

However, since this technique is very sensitive to the presence of atypical observations in data, we adopt the robust order- $m$ estimation method introduced by Cazals et al (2002). This approach is related to the FDH estimator, but instead of constructing a full frontier, it creates a partial frontier that envelops only $m(\geqslant 1)$ observations randomly drawn with replacement from the empirical sample. This procedure is repeated $B$ times resulting in multiple measures $\left(\hat{\lambda}_{m i}^{1}, \ldots, \hat{\lambda}_{m i}^{B}\right)$ from which the final order- $m$ efficiency measure is computed as the simple mean $\left(\hat{\lambda}_{m i}\right)$. Specifically, the order- $m$ estimated efficiency score is derived from Equation (3) as follows:

$$
\hat{\lambda}_{m}=E\left[\min _{i=1, \ldots, m}\left\{\max _{j=1, \ldots, p}\left(\frac{x_{i}^{j}}{x^{j}}\right)\right\} \mid y_{i} \geqslant y\right]
$$

where the $\rho$-dimensional random variables $x_{i}, \ldots, x_{m}$ are drawn randomly and repeatedly from the conditional distribution of $X$ given $y_{i} \geqslant y$. For acceptable $m$ values, the efficiency scores will present values higher than unity, which indicates that schools are inefficient, as outputs can be increased without modifying the level of inputs. When $\hat{\lambda}<1$, the unit can be labelled as superefficient, since the order- $m$ frontier exhibits lower levels of outputs than the unit under analysis (Daraio and Simar, 2007a).

\section{The metafrontier approach}

Given that our data has a hierarchical structure (schools operating in different countries), we adapt the concept of a metafrontier developed by Battese and Rao (2002), Battese et al (2004) and O'Donnell et al (2008). This approach measures the efficiency of units relative to separate best practice frontiers and allows us to decompose which part of the performance can be attributed to the schools and which part depends on country factors. This approach is basically an extension of the decomposition of school effect from students' inefficiency introduced by Ruggiero (2000), Silva-Portela and Thanassoulis (2001) and Thanassoulis and Silva-Portela (2002). Therefore, the case of schools operating within a country can be derived straightforward.

If we consider $K$ different educational systems, each having its own distinctive features, a metafrontier is defined as the boundary of the unrestricted technology set. Hence, the metafrontier envelops each of the separate group frontiers (one frontier for each country). Separately, the local efficiency of the schools with regard to the special characteristics of the country where it is operating is measured relative to the $n_{k}$ observations in the school sample. If all the countries have the same characteristics, all the observations can be pooled and schools can be evaluated relative to the same standards. As a result, two different frontiers are estimated: the local frontier specific for each educational system and the overall frontier. The distance to the local frontier depends only on the school efficiency ( $S C E)$ whereas the distance separating the local and the overall frontier can be interpreted as the country effect $(C N E)$. This can be illustrated in Figure 1, where the efficiency level of each school $c$ depends on the level of the output achieved $\left(y_{c}\right)$ using their input endowment $\left(x_{c}\right)$. This school is inefficient, since there are other schools operating in the same educational system obtaining better results $\left(y^{\prime}\right)$ with the same amount of inputs $\left(x_{c}\right)$. The

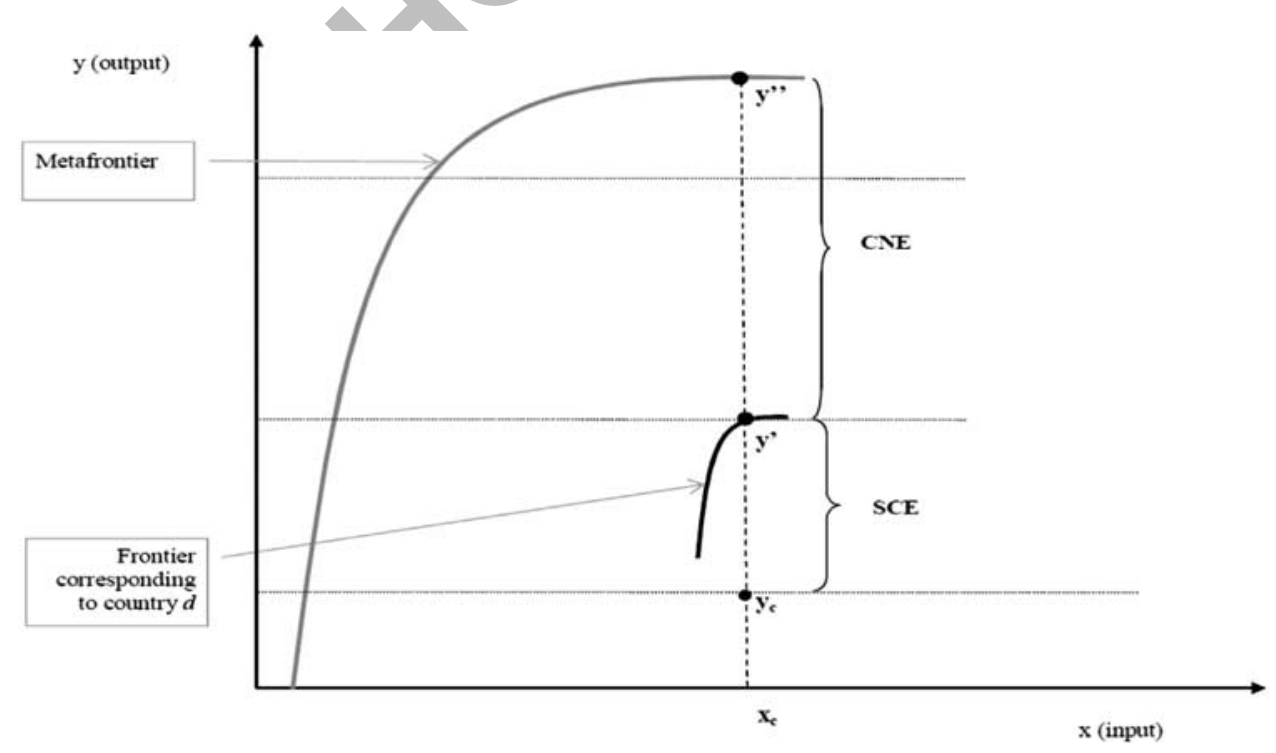

Figure 1 Metafrontier illustration (decomposition of school and country effect). 
school inefficiency can be defined by the ratio between the local potential output divided by the actual output $\left(S C E=y^{\prime} / y_{c}\right)$. When this school is compared with the metafrontier, the overall efficiency $(O E)$ can be defined as $O E=y^{\prime \prime} / y_{c}$. From those two measures of efficiency, the country effect can be automatically derived as $C N E=y^{\prime \prime} / y^{\prime}=O E / S C E$. In summary, the global efficiency can be decomposed in two effects: $O E=S C E \times$ CNE.

\section{The robust and conditional FDH model}

Once we have decomposed the efficiency of each school, the final step of our analysis consists of considering the effect of some exogenous variables $Z \in \mathfrak{R}_{+}^{k}$, affecting the performance of schools. If we do not consider the existing heterogeneity among schools, we would be implicitly assuming that all the schools are operating with the most favourable environment, which would not be real in many situations (Ruggiero, 1996). In our case, we are interested in testing the potential influence of some external variables at school level, but we also account for potential specific features at country level that can affect the performance of schools. For that purpose, we use the full nonparametric conditional approach developed by Cazals et al (2002) and Daraio and Simar (2005, 2007a, b), which assumes that both types of factors can have a direct influence on the shape of the best practice frontier (ie, this model does not assume a separability condition). Therefore, efficiency estimates are determined by inputs, outputs and exogenous variables. Using a probabilistic formulation, this conditional function can be defined as:

$$
\begin{aligned}
\left.H_{X Y \mid Z}(x, y \mid z)\right)= & \operatorname{Pr}(Y \geqslant y \mid x \leqslant x, Z=z) \\
& \operatorname{Pr}(X \leqslant x, Z=z) \\
= & S_{Y \mid X, Z}(Y \geqslant y \mid X \leqslant x, Z=z) \\
& F_{X}(X \leqslant x ; Z=z)=S_{Y}(y \mid x, z) F_{X}(x \mid z)
\end{aligned}
$$

The function $H_{X Y Y Z}(x, y \mid z)$ represents the probability of a unit operating at level $(x, y)$ being dominated by other units facing the same environmental conditions $z$. Using this formulation, the conditional order- $m$ efficiency estimator can be defined as:

$$
\hat{\lambda}_{m}(x, y \mid z)=\int_{0}^{\infty}\left[1-\left(1-\hat{S}_{Y \mid X}(u y \mid x, z)\right)^{m}\right] d u
$$

The estimation of $S_{Y}(y \mid x, z)$ is more difficult than the unconditional case, because it requires using smoothing techniques for the exogenous variables in $z$ (due to the equality constraint $Z=z$ ):

$$
\hat{S}_{Y, n}(y \mid x, z)=\frac{\sum_{i=1}^{n} I\left(x_{i} \leqslant x, y_{i} \geqslant y\right) K_{\hat{h}}\left(z, z_{i}\right)}{\sum_{i=1}^{n} I\left(x_{i} \leqslant x\right) K_{\hat{h}}\left(z, z_{i}\right)}
$$

This approach relies therefore on the estimation of a nonparametric kernel function to select the appropriate reference partners and a bandwidth parameter $h$ using some bandwidth choice method. In our case, we follow the data-driven selection approach developed by Badin et al (2010) and we use a generalized product kernel function, since we have mixed data (continuous and discrete variables) in our data set (see De Witte and Kortelainen, 2013, for details).

This conditional model allows us to evaluate the direction of the effect of external variables on the production process by comparing conditional with unconditional measures. In particular, Daraio and Simar (2005, 2007a) suggest using a scatter plot of the ratio between these measures $\left(Q^{z}=\right.$ $\left.\hat{\lambda}_{m}(x, y \mid z) / \hat{\lambda}_{m}(x, y)\right)$ against $Z$ and its smoothed nonparametric regression line. In an output-oriented conditional model, an increasing regression line will indicate that $Z$ is favourable to efficiency whereas a decreasing line will denote an unfavourable effect. Similarly, it is also possible to investigate the statistical significance of $Z$ explaining the variations of $Q$. For that purpose, we use local linear least squares for regression estimation as recommended by Badin et al (2010) and Jeong et al (2010). We then apply the nonparametric regression significance test proposed by Li and Racine (2004) and Racine and Li (2004), which smooths both continuous and discrete variables. Specifically, we test the significance of each of the continuous and discrete variables using bootstrap tests proposed by Racine et al (2006) and Racine (1997), which can be interpreted as the nonparametric equivalent of standard $t$-tests in ordinary least squares regression (De Witte and Kortelainen, 2013)

\section{Data and variables}

In this study we use data from schools in European countries participating in PIRLS 2011. This data set provides international comparative data about students' reading achievement in the fourth year of primary schooling as well as a rich array of background information about students' socioeconomic status, the school environment and instructional practices (see Mullis et al, 2012, for details). This information comes from the responses given to different questionnaires completed by students, parents, teachers and school principals.

As we are interested in accounting for some specific characteristics of the countries where those schools are operating, we also retrieved data about different economic and social aspects from two additional sources. The economic information was collected from the World Bank Open Data section, while social indicators about cultural values come from pooled data about the five aggregate waves of the WVS.

Given that some of the European countries participating in PIRLS 2011 were not included in the WVS database, we had to restrict our analysis to only 16 countries for which we had data available from all the sources. Therefore, our final data set comprises a total number of 2398 schools distributed across countries as it is shown in Table 1 .

The output variable is represented by the average of the results in reading of students attending the same school (PVREAD). These results are not expressed by only one value, 
Table 1 Data set composition: number of schools in each country

\begin{tabular}{lclc}
\hline Countries & $\begin{array}{c}\text { Number of } \\
\text { schools }\end{array}$ & Countries & $\begin{array}{c}\text { Number of } \\
\text { schools }\end{array}$ \\
\hline Bulgaria & 140 & Lithuania & 137 \\
Czech Republic & 153 & Netherlands & 128 \\
Finland & 121 & Norway & 101 \\
France & 138 & Poland & 116 \\
Georgia & 136 & Romania & 125 \\
Germany & 187 & Slovenia & 182 \\
Hungary & 124 & Spain & 278 \\
Italy & 190 & Sweden & 142 \\
TOTAL & 2398 & & \\
\hline
\end{tabular}

but by five denominated plausible values randomly obtained from the distribution function of test results derived from the answers in each test (Rasch, 1960, 1980), which can be interpreted as the representation of the ability range for each student (Mislevy et al, 1992; Wu and Adams, 2002). As baseline results, in our analysis we have only used one (the first) of the plausible values and, subsequently, we have used each of the other four values as a robustness test. Owing to space restrictions, we only present the estimations obtained with that first value, although the results of the empirical analysis are quite similar with the others.

The decision about which variables should be included as inputs is one of the main challenges of empirical studies using data from an international survey, since it usually includes an extensive list of potential indicators that can be considered. In this sense, most empirical papers attempting to measure efficiency of schools usually include some measure of human and capital resources (the interested reader can refer to Worthington, 2001 or Bradley et al, 2001 for early reviews or De Witte, 2014 for a recent update). In our case, we have decided to include the number of teachers in the model following the same criterion of many previous studies (eg Cordero et al, 2010; Brennan et al, 2014; Essid et al, 2014). Similarly, we include two variables that have been identified in the literature as main contributors to the attainment such as the instruction time (Lavy, 2010; Rivkin and Schiman, 2013) and the number of computers (Spiezia, 2010).

The inclusion of the characteristics of the students (usually represented by their socioeconomic status-SES-) among inputs is more discussed. Although the role of SES in explaining the students and schools' educational results is unquestionable (Haveman and Wolfe, 1995), thus it should be considered an input as in Agasisti (2014), Thieme et al (2013) or CrespoCebada et al (2014); however, some authors propose to include measures of SES as non-discretionary inputs (see Ruggiero and Vitaliano, 1999). In this paper, we have included this variable as a traditional input so that schools are evaluated according to their ability of making the most with their inputs (see Bradley et al, 2001 and Camanho et al, 2009, for details). Unfortunately, unlike PISA data set, PIRLS does not provide an index representing SES; therefore, we have constructed it through principal component analysis (Jobson, 1992) as we describe below.

The following list summarizes our four input variables included in the empirical analysis based on the criterion of selecting variables representing different dimensions of school resources:

Number of teachers per a hundred students (TEACH100).

Instruction hours per week (INSTIME).

Number of computers per a hundred students (COMP100).

A composed index representing the socioeconomic status of pupils (SES). Following a similar criterion of the Economic Social and Cultural Status (ESCS) in PISA, we derived this index from data about the level of education of both parents and the number of books at home. As those variables were strongly correlated with each other, one factor was sufficient to explain most of the original variance (69\%). Similarly, the original positive and negative values were rescaled to present positive values.

Regarding the variables representing the environment in which the school is operating, we take into account two different sources of heterogeneity: at school level and those specific country features. The first one includes a mixed set of six indicators with theoretical support in the literature. In particular, there are two continuous variables representing early literacy skills of students before entering the primary grades (EARLIT) (see Foy and Drucker, 2013, for details about its construction) and the average level of classroom disciplinary climate perceived by students attending the same school (DISCPL). There are also two ordered discrete variables that allow us to take into account the parental involvement at home (INVHOME) and in school (INVSCHL) and two (unordered) dummy variables regarding whether there is problem of absenteeism at the school (ABSENT) and whether the school is placed in a rural area (RURAL). These latter variables were rescaled to have a value equal to 1 for those conditions and equal to 2 otherwise.

The second group is composed of five continuous indicators about economic and cultural aspects collected at country level. The two economic variables are represented by the gross domestic product (GDP) per capita and the public expenditure per student in primary education as a percentage of GDP per capita for each country in the year 2011. On the other hand, as we mentioned previously, the source for information about cultural values in each country is the WVS. This data set provides information on individual socio-economic variables, attitudes and values regarding multiple aspects of life collected through a standardized survey. In particular we use information provided from a set of questions about which qualities are most valued when raising a child. Specifically, respondents are given a list of qualities (independence, hard work, feeling of responsibility, imagination, tolerance, thrift, perseverance, religious faith, unselfishness and obedience) that children can 
Table 2 Descriptive statistics of variables included in the analysis

\begin{tabular}{llrrrr}
\hline Variable & Type & Mean & $\begin{array}{c}\text { Std. } \\
\text { Dev. }\end{array}$ & Min & Max \\
& & & & \\
\hline PVREAD & Output & 529.99 & 37.51 & 330.39 & 619.56 \\
SES & Input & 2.18 & 0.60 & 0.01 & 3.93 \\
TEACH100 & Input & 4.80 & 1.22 & 1.08 & 18.18 \\
COMP100 & Input & 5.53 & 4.35 & 0.07 & 73.05 \\
INSTIME & Input & 15.90 & 3.36 & 9.23 & 31.54 \\
& & & & & \\
School factors & & & & & \\
EARLIT & Continuous & 9.76 & 0.85 & 5.26 & 12.19 \\
DISCPL & Continuous & 10.12 & 1.65 & 3.65 & 13.16 \\
INVHOME & Ordered & 3.32 & 0.52 & 1.00 & 4.00 \\
& discrete & & & & \\
INVSCHL & Ordered & 3.03 & 0.79 & 1.00 & 5.00 \\
& discrete & & & & \\
ABSENT & Unordered & 1.47 & 0.75 & 1.00 & 4.00 \\
& discrete & & & & \\
RURAL & Unordered & 1.40 & 0.49 & 1.00 & 2.00 \\
& discrete & & & & \\
Country features & & & & & \\
GDP pc & Continuous & 31486 & 21301 & 3220 & 99173 \\
EXPEDUC & Continuous & 21.84 & 4.46 & 13.21 & 31.1 \\
HARDWORK & Continuous & 0.48 & 0.28 & 0.07 & 0.90 \\
RESP & Continuous & 0.78 & 0.09 & 0.57 & 0.91 \\
PERSEV & Continuous & 0.41 & 0.10 & 0.26 & 0.56 \\
\hline & & & & &
\end{tabular}

be encouraged to learn at home and then asked to choose up to five that they think are most important.

According to Heckman (2011), there are 'Big Five' dimensions of personality skills (Conscientiousness, Openness to Experience, Extraversion, Agreeableness and Emotional Stability). Among them, factor 'Conscientiousness' can be defined as the tendency to be organized, responsible and hardworking. Heckman (2011) shows that this Conscientiousness factor is the most highly correlated with education outcomes (course grades and years of schooling). Borghans and Schils (2012) study the development of the performance of students during the test finding that Conscientiousness turns out to be associated with a smaller performance drop in correct responses between the beginning and the end of the test. For this reason, we have only selected answers for the three variables directly related to the conscientiousness factor: hard work (HARDWORK), responsibility (RESP) and perseverance (PERSEV). Table 2 reports the descriptive statistics for all these variables. In addition, Table 3 includes their mean values for each country in order to facilitate the interpretation of results shown in the next section.

\section{Results}

Table 4 reports the average estimated efficiency scores of schools operating in each country for the unconditional model as well as the decomposition between the school effect and the country effect using the metafrontier approach. Those scores have been estimated using the robust order- $m$ model with an output orientation, since we consider that schools are always attempting to maximize their attainment and cannot easily reduce their inputs, at least in the short term. The estimation of overall efficiency is obtained using the whole sample, whereas the decomposition between the school effect and country effect requires the estimation of 16 local frontiers (one for each country). To avoid the problem of bias that might arise because there is a dissimilarity in sample sizes across countries, we follow the same criterion established in De Witte and Marques (2009), which consists of setting $m$ equal to the smallest local data set (ie Norway). Therefore, we set $m=100$ to estimate all the local frontiers as well as the overall frontier; thus, every unit is compared with the same number of schools in all the estimations. For statistical inference, we use 200 bootstrap replications following the recommendation made by Daraio and Simar (2005, p 103).

In the last row of the table, we can observe that the average value of the overall efficiency for all the schools in the sample is 1.0759, which indicates that if all schools would perform as efficiently as the best school performers, the test scores could increase on average by $7 \%$ (or $10 \%$ if we only consider the inefficient units). Similarly, it is worth noting that some schools have a performance score below one. These super-efficient schools are performing better than the 100 schools they are benchmarked with. With regard to the average scores of units operating in different educational systems, the three top-listed countries are Finland, Bulgaria and the Netherlands, while the schools with the worst performance are operating in France, Slovenia, Norway and Georgia. Although there are some similarities with the ranking of countries according to their results shown in Table 3 (Finland and Georgia are placed at the top and the bottom, respectively, in both rankings), we can observe that the consideration of the inputs of educational process in the efficiency analysis makes some countries improve their position in the ranking. For instance, the incorporation of the socioeconomic status in the model benefits schools operating in Romania, since they have the lowest average levels. Something similar occurs with Bulgarian schools, which are placed at the second place in the ranking after considering their limited educational resources. In contrast, Germany occupies a lower position when educational inputs are taken into account since this country presents higher values than the average in most input variables.

If we focus on the decomposition of this overall efficiency, it is possible to find that, on average, the inefficiency levels detected can be attributed to a greater extent to the operating environment in the country (around 60\%) than to the school context (around 40\%). However, it is possible to find significant differences across countries. For instance, most part of the inefficiency in schools operating in Italy $(86 \%)$ or Bulgaria (79\%) depend on specific school factors, while in Norway, Georgia or Sweden the country effect is quite more relevant $(85$, 80 and $76 \%$, respectively) to explain the levels of inefficiency of their schools. 
Table 3 Mean values of all variables for each country (countries ranked by results in reading)

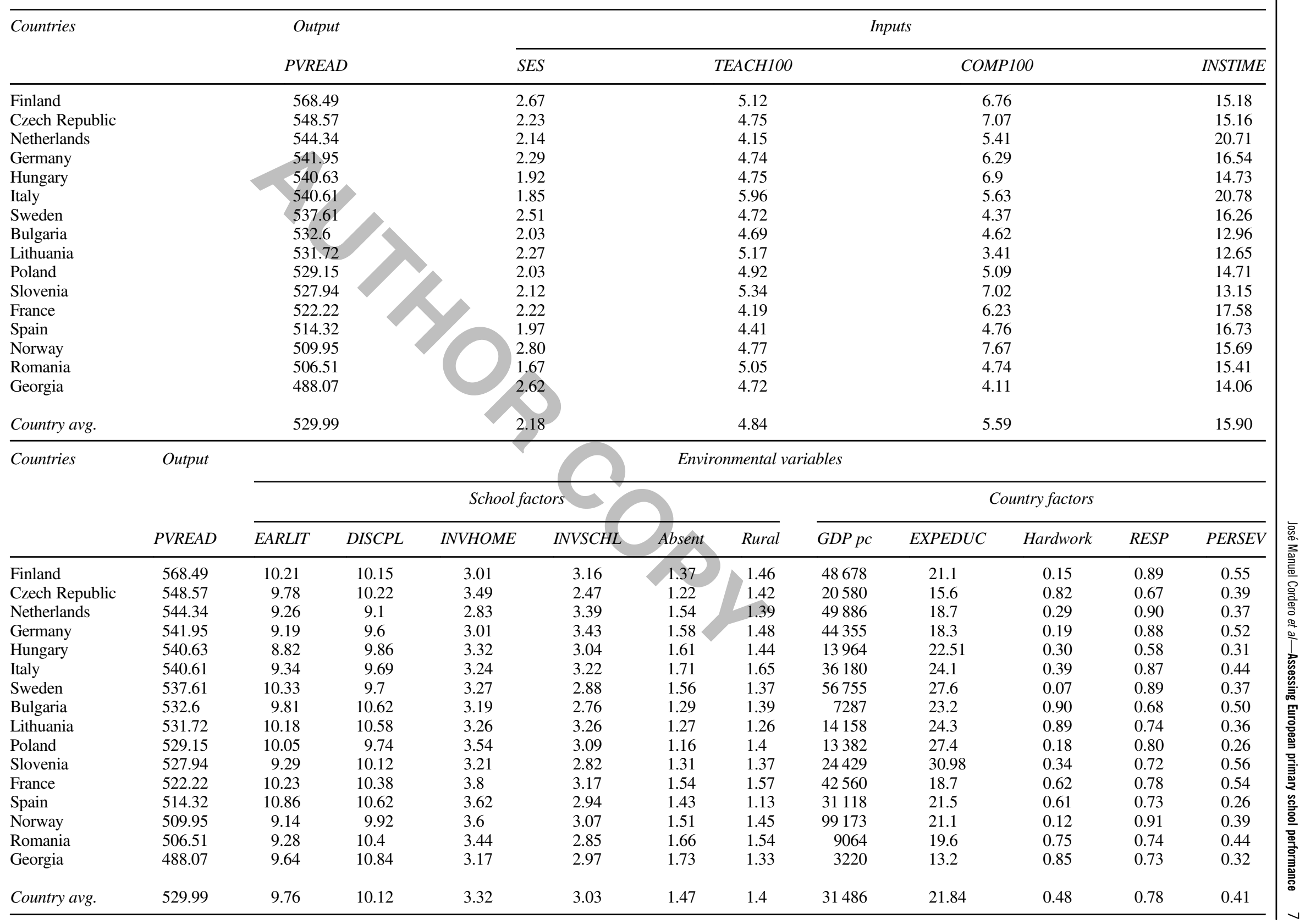


Table 4 Decomposition of overall efficiency between school and country effect for each country

\begin{tabular}{|c|c|c|c|c|c|c|c|c|c|}
\hline \multirow[t]{2}{*}{ Countries } & \multicolumn{4}{|c|}{ Overall efficiency } & \multicolumn{5}{|c|}{ School effect } \\
\hline & Mean & $S T$ & Min & $\operatorname{Max}$ & Mean & $\%$ & $S T$ & Min & $\operatorname{Max}$ \\
\hline Finland & 1.0432 & 0.0342 & 0.9764 & 1.1358 & 1.0208 & 48.11 & 0.0298 & 1.0000 & 1.1059 \\
\hline Bulgaria & 1.0442 & 0.0772 & 0.9921 & 1.4440 & 1.0347 & 78.64 & 0.0735 & 1.0000 & 1.4439 \\
\hline Netherlands & 1.0450 & 0.0478 & 0.9891 & 1.2111 & 1.0182 & 40.46 & 0.0289 & 0.9995 & 1.1551 \\
\hline Hungary & 1.0456 & 0.0584 & 0.9782 & 1.2729 & 1.0160 & 35.18 & 0.0297 & 0.9995 & 1.1518 \\
\hline Lithuania & 1.0476 & 0.0525 & 0.9996 & 1.2159 & 1.0228 & 47.86 & 0.0353 & 0.9998 & 1.1713 \\
\hline Czech Republic & 1.0510 & 0.0480 & 0.9931 & 1.2500 & 1.0187 & 36.62 & 0.0285 & 0.9953 & 1.1164 \\
\hline Italy & 1.0611 & 0.0685 & 0.9512 & 1.5774 & 1.0526 & 86.09 & 0.0594 & 0.9996 & 1.2119 \\
\hline Poland & 1.0642 & 0.0614 & 0.9941 & 1.2935 & 1.0174 & 27.15 & 0.0330 & 0.9926 & 1.1689 \\
\hline Germany & 1.0685 & 0.0577 & 0.9867 & 1.3744 & 1.0281 & 41.01 & 0.0412 & 0.9980 & 1.2178 \\
\hline Romania & 1.0771 & 0.0925 & 0.9961 & 1.4585 & 1.0239 & 30.97 & 0.0481 & 1.0000 & 1.2447 \\
\hline Spain & 1.0822 & 0.0725 & 0.9983 & 1.3822 & 1.0465 & 56.57 & 0.0563 & 0.9997 & 1.2937 \\
\hline Sweden & 1.0824 & 0.0588 & 0.9968 & 1.3170 & 1.0190 & 23.01 & 0.0300 & 0.9969 & 1.1282 \\
\hline France & 1.0871 & 0.0583 & 0.9909 & 1.2814 & 1.0335 & 38.48 & 0.0411 & 0.9993 & 1.1939 \\
\hline Slovenia & 1.0970 & 0.0649 & 0.9944 & 1.3260 & 1.0335 & 34.48 & 0.0408 & 0.9842 & 1.2402 \\
\hline Norway & 1.1606 & 0.0586 & 1.0000 & 1.3080 & 1.0207 & 12.91 & 0.0310 & 0.9994 & 1.1304 \\
\hline Georgia & 1.1684 & 0.1106 & 1.0000 & 1.4840 & 1.0285 & 16.94 & 0.0448 & 0.9984 & 1.1946 \\
\hline Total & 1.0759 & 0.0747 & 0.9512 & 1.5774 & 1.0293 & 38.57 & 0.0455 & 0.9842 & 1.4439 \\
\hline
\end{tabular}

Countries

Country effect

\begin{tabular}{|c|c|c|c|c|c|}
\hline & \\
\hline & Mean & $\%$ & $S T$ & Min & $\operatorname{Max}$ \\
\hline Finland & 1.0222 & 51.46 & 0.0287 & 0.9764 & 1.1358 \\
\hline Bulgaria & 1.0092 & 20.76 & 0.0244 & 0.9762 & 1.1473 \\
\hline Netherlands & 1.0262 & 58.28 & 0.0343 & 0.9891 & 1.1917 \\
\hline Hungary & 1.0293 & 64.16 & 0.0528 & 0.9782 & 1.2729 \\
\hline Lithuania & 1.0243 & 51.00 & 0.0378 & 0.9986 & 1.2159 \\
\hline Czech Republic & 1.0316 & 61.99 & 0.0338 & 0.9931 & 1.1335 \\
\hline Italy & 1.0089 & 14.59 & 0.0544 & 0.9514 & 1.5774 \\
\hline Poland & 1.0459 & 71.48 & 0.0484 & 0.9986 & 1.2319 \\
\hline Germany & 1.0397 & 57.91 & 0.0479 & 0.9867 & 1.3744 \\
\hline Romania & 1.0516 & 66.88 & 0.0689 & 0.9712 & 1.3054 \\
\hline Spain & 1.0340 & 41.40 & 0.0395 & 0.9974 & 1.2385 \\
\hline Sweden & 1.0625 & 75.76 & 0.0527 & 0.9968 & 1.3170 \\
\hline France & 1.0519 & 59.63 & 0.0409 & 0.9894 & 1.2119 \\
\hline Slovenia & 1.0613 & 63.18 & 0.0414 & 0.9945 & 1.2132 \\
\hline Norway & 1.1371 & 85.33 & 0.0464 & 1.0000 & 1.2585 \\
\hline Georgia & 11255 & 80.47 & 0.0903 & 1.0000 & 1.4546 \\
\hline Total & 1.0455 & 59.87 & 0.0590 & 0.9514 & 1.5774 \\
\hline
\end{tabular}

The main problem of this initial assessment is that they are based on the assumption that all the evaluated schools are operating in the same environment, so the estimated performance scores may not adequately represent their level of efficiency. Therefore, the next step consists of considering the existing heterogeneity among schools in our estimation of their efficiency scores. For that purpose, two alternative conditional efficiency models have been developed. These models include stepwise additional information about variables representing the environment as in Haelermans and De Witte (2012). In model 1 we only consider a mixed set of continuous and discrete variables related to the school environment (location, students' early skills, parental involvement, absenteeism and disciplinary levels). Subsequently, we estimate a second conditional model (model 2) including an additional set of economic and cultural values associated with each country. The results obtained for both models are reported in Table 5, where we also distinguish the average efficiency of schools across countries.

Once we include information about environmental variables in the analysis the average efficiency decreases in both models (1.0536 for model 1 and 1.0315 for model 2 ). This is intuitive since the consideration of additional variables in the analysis implies that the reference group only includes schools with more similar characteristics. However, the most interesting 
Table 5 Efficiency score distribution across countries in different models

\begin{tabular}{|c|c|c|c|c|c|c|c|c|}
\hline \multicolumn{3}{|l|}{ Unconditional } & \multicolumn{3}{|c|}{ Conditional model 1} & \multicolumn{3}{|c|}{ Conditional model 2} \\
\hline & Mean & $S T$ & & Mean & $S T$ & & Mean & $S T$ \\
\hline Finland & 1.0432 & 0.0342 & Hungary & 1.0257 & 0.0417 & Hungary & 1.0166 & 0.0318 \\
\hline Bulgaria & 1.0442 & 0.0772 & Bulgaria & 1.0268 & 0.0655 & Finland & 1.0194 & 0.0261 \\
\hline Netherlands & 1.0450 & 0.0478 & Netherlands & 1.0289 & 0.0375 & Czech Republic & 1.0198 & 0.0276 \\
\hline Hungary & 1.0456 & 0.0584 & Czech Republic & 1.0329 & 0.0364 & Netherlands & 1.0199 & 0.0306 \\
\hline Lithuania & 1.0476 & 0.0525 & Finland & 1.0331 & 0.0319 & Poland & 1.0211 & 0.0362 \\
\hline Czech Republic & 1.0510 & 0.0480 & Lithuania & 1.0347 & 0.0450 & Sweden & 1.0220 & 0.0311 \\
\hline Italy & 1.0611 & 0.0685 & Italy & 1.0405 & 0.0627 & Bulgaria & 1.0240 & 0.0621 \\
\hline Poland & 1.0642 & 0.0614 & Poland & 1.0442 & 0.0507 & Germany & 1.0268 & 0.0351 \\
\hline Germany & 1.0685 & 0.0577 & Romania & 1.0451 & 0.0751 & Lithuania & 1.0293 & 0.0434 \\
\hline Romania & 1.0771 & 0.0925 & Spain & 1.0513 & 0.0610 & Norway & 1.0302 & 0.0464 \\
\hline Spain & 1.0822 & 0.0725 & Germany & 1.0523 & 0.0491 & Slovenia & 1.0345 & 0.0421 \\
\hline Sweden & 1.0824 & 0.0588 & Sweden & 1.0594 & 0.0504 & France & 1.0352 & 0.0427 \\
\hline France & 1.0871 & 0.0583 & France & 1.0626 & 0.0507 & Romania & 1.0371 & 0.0721 \\
\hline Slovenia & 1.0970 & 0.0649 & Slovenia & 1.0665 & 0.0629 & Spain & 1.0424 & 0.0536 \\
\hline Norway & 1.1606 & 0.0586 & Georgia & 1.1327 & 0.1057 & Italy & 1.0430 & 0.0543 \\
\hline Georgia & 1.1684 & 0.1106 & Norway & 1.1399 & 0.0643 & Georgia & 1.0657 & 0.0800 \\
\hline Total & 1.0759 & 0.0747 & Total & 1.0536 & 0.0656 & Total & 1.0315 & 0.0489 \\
\hline
\end{tabular}

conclusions can be drawn by exploring the distribution of the efficiency scores across countries in both rankings. In this sense, the ranking of countries according to their average results with model 1 does not suffer significant alterations with respect to the unconditional model. Actually, the Spearman correlation coefficient between the two distributions of schools is quite high (0.849). The only remarkable change in the ranking of countries is represented by Hungary, which is considered the top performer within this model, while Finland descends from the top seed in the unconditional model to the fifth position in this model.

Nevertheless, the consideration of country features in model 2 modifies the picture to a large extent (Spearman correlation coefficient with the unconditional case is now 0.658). In particular, schools operating in Norway, Sweden and Georgia, where the country effect was very relevant according to the information showed in Table 4, experienced a substantial improvement in their average level of inefficiency, although the latter still maintains at the bottom of the ranking. In contrast, other countries in which the specific country features were not too relevant such as Italy or Bulgaria worsen their relative positions with respect to other countries. The importance of those changes leads us to presume that the heterogeneity among different countries is more relevant than heterogeneity among schools within the same country.

In order to examine the influence of those external factors on efficiency estimates, we regress the ratio between the conditional and the unconditional efficiency scores on the environmental variables using the local linear estimator described in the methodology section. As we have two different models (model 1 and model 2), we have also carried out two different estimations. Table 6 presents the median influence of these variables and the $p$-values of the significance tests proposed by $\mathrm{Li}$ and Racine (2004) and Racine and Li (2004) after performing 1000 bootstrap samples. Moreover, we indicate whether a variable has a favourable or unfavourable correlation with efficiency according to the visualization of the partial regression scatter plots.

In model 1, almost all the external school variables seem to have a significant effect on explaining the level of inefficiency. In particular, we detect a negative influence of being placed in a rural area, which is usually related to the lack of competitive pressure rather than the location itself (Alchian, 1950). Similarly, the parental involvement at home and school has a positive and significant effect on performance as pointed out by multiple previous literature focused on the determinants of students' attainment (see Wilder, 2014, for an extensive review on this topic). Finally, variables representing school environment, such as the level of disciplinary climate in the classroom or the existence of a problem of absenteeism in the school, are also significantly related (positive and negative, respectively) to school efficiency. In contrast, the early literacy skills of students before entering the school is not considered as a relevant factor to explain school efficiency probably because its effect was captured by the SES input.

The results of model 2, in which we account for heterogeneity across countries, reveal that all variables representing specific country features of countries have a significant and positive influence on efficiency, whereas the influence of school variables becomes insignificant for all the considered indicators. Therefore, we can conclude that country factors seem to have a more relevant role in explaining differences in the performance of schools because there is more heterogeneity across countries than among schools. One potential explanation for this result is 
Table 6 Influence of different factors on educational performance (estimation of nonparametric significance tests)

\begin{tabular}{|c|c|c|c|c|}
\hline \multirow[t]{2}{*}{ School variables } & \multicolumn{2}{|c|}{ Model 1} & \multicolumn{2}{|c|}{ Model 2} \\
\hline & p-value & $\begin{array}{l}\text { Influence } \\
\text { (scatter plot) }\end{array}$ & p-value & $\begin{array}{l}\text { Influence } \\
\text { (scatter plot) }\end{array}$ \\
\hline Disciplinary index & $0.01 *$ & Favourable & 0.99 & Favourable \\
\hline Earlit & 0.95 & Favourable & 0.99 & Favourable \\
\hline $\begin{array}{l}\text { Parents' } \\
\text { involvement at } \\
\text { home }\end{array}$ & $0.00 * * *$ & Favourable & 0.99 & Favourable \\
\hline $\begin{array}{l}\text { Parents' } \\
\text { involvement in } \\
\text { school }\end{array}$ & $0.01 *$ & Favourable & 0.99 & Favourable \\
\hline Rural area & $0.00 * * *$ & Unfavourable & 0.99 & Unfavourable \\
\hline Absenteeism & $0.00 * * *$ & Unfavourable & 0.99 & Unfavourable \\
\hline Country variables & & & $p$-value & $\begin{array}{l}\text { Influence } \\
\text { (scatter plot) }\end{array}$ \\
\hline GDP pc & & & $0.00 * * *$ & Favourable \\
\hline $\begin{array}{l}\text { Expenditure in } \\
\text { education }\end{array}$ & & & $0.00 * * *$ & Favourable \\
\hline Hard work & & & $0.00 * * *$ & Favourable \\
\hline Responsibility & & & $0.00 * * *$ & Favourable \\
\hline Perseverance & & & $0.00 * * *$ & Favourable \\
\hline
\end{tabular}

$* * *$ denotes statistical significance at $1 \%$.

*denotes statistical significance at $10 \%$.

that our sample only includes European countries, where the school context is relatively similar.

This finding about the scarce influence of specific school factors is in line with some previous results in the literature for a specific country (eg, Haelermans and De Witte, 2012, for the Netherlands) as well as the important role played by economic indicators to explain differences in efficiency performance across countries (eg, Afonso and St Aubyn, 2006). Nevertheless, the importance of cultural or personality factors as determinants of educational performance has only been considered as a relevant factor in some recent cross-country studies (eg, Borghans et al, 2008; Borghans and Schils 2012; Conti et al, 2011). Our contribution here is that coinciding with previous results we found that the conscientiousness factor also has a significant influence to explaining differences in efficiency estimates. From this result it is worth to remark that more attention should be devoted to non-cognitive skills in order to boost efficiency in education.

\section{Concluding remarks}

In this paper we have combined the use of two totally nonparametric methods to assess the performance of primary schools in 16 European countries using data from PIRLS 2011. Specifically, we adapt the metafrontier approach developed by Battese and Rao (2002), Battese et al (2004) and O'Donnell et al (2008) to our context with the aim of decomposing which part of the estimated inefficiency can be attributed to the school and the country. Subsequently, we apply the robust conditional model developed by Daraio and Simar (2005, 2007a,b) and extended by De Witte and Kortelainen (2013) to account for two different sets of variables related to the school and the country environment. Similarly, nonparametric bootstraps based on significance tests have been applied to examine the statistical influence of those factors on efficiency scores.

Our results show that the ranking of countries based only on academic results modifies in a certain extent when we account for data about school inputs participating in the educational process in our efficiency analysis. As a result, schools in which the average socioeconomic status of the students is relatively low improve their relative position, while schools having better resource endowments descend in the ranking when this information is taken into account. Similarly, the decomposition of inefficiency between the school and country effect allows us to detect significant divergences across countries with regard to which are the main explanatory factors for their inefficient performance. In this sense, the results indicate that heterogeneity across countries is more relevant than among schools. In particular, we would like to highlight the significant and positive effect of cultural non-cognitive values, since those factors have been scarcely studied so far in the efficiency literature. However, the approach used in this paper does not allow for a causal interpretation of the results but it allows pointing out to a future line of research based on the search of the causes of inefficiency.

These findings provide some interesting insights into the analysis of determinants of educational attainment using a crosscountry approach. However, more research will be needed in future to explore more in depth the results discussed here. First, it would be interesting to replicate this type of analysis using data about secondary schools, since the performance of students in those levels might also be affected by the existence of school tracking or external exams - accountability - in some countries (see Woessman et al, 2009 or Hanushek and Woessmann, 2014, for details). Those types of policies have not been considered in this study because students evaluated in PIRLS are enrolled in the fourth grade of primary school; thus, basically they are not affected by them.

Second, the analysis of divergences between public and private schools remains as an appealing field for future research using the model proposed in this paper. Unfortunately, in our empirical analysis we could not deal with this aspect, since this information is not available in PIRLS for the majority of countries. Similarly, the proposed analysis could be replicated using data at pupil level. Actually, these data have been used in some recent studies to assess the performance of students in a specific country (eg Perelman and Santín, 2011; De Witte and Kortelainen, 2013). However, it must be taken into account that the estimation of the kernel bandwidths and the efficiency scores with conditional models can take a great amount of time (even for months) given the huge sample sizes of international large-scale data sets. 
Acknowledgements_-The authors would like to thank Professors Mika Kortelainen and Kristof De Witte for providing us with the codes for estimating the conditional efficiency scores. Likewise, the authors would like to express gratitude to the participants in the 2014 Asia-Pacific Productivity Conference in Brisbane and the Workshop on Efficiency in Education in London for valuable comments, two anonymous referees for helpful suggestions and personnel working at CENITS for their support in the use of LUSITANIA computer resources. Research support from Ramon Areces Foundation and Gobierno de Extremadura (Project IB13106) is also acknowledged by the authors.

\section{References}

Afonso A and St Aubyn M (2006). Cross-country efficiency of secondary education provision: A semi-parametric analysis with nondiscretionary inputs. Economic Modelling 23(3): 476-491.

Agasisti T (2014). The efficiency of public spending on education: An empirical comparison of EU countries. European Journal of Education 49(4): 543-557.

Alchian AA (1950). Uncertainty, evolution and economic theory. Journal of Political Economy 58(3): 211-221.

Aristovnik A and Obadić A (2014). Measuring relative efficiency of secondary education in selected EU and OECD countries: The case of Slovenia and Croatia. Technological and Economic Development of Economy 20(3): 419-433.

Badin L, Daraio C and Simar L (2010). Optimal bandwidth selection for conditional efficiency measures: A data-driven approach. European Journal of Operational Research 201(2): 633-640.

Barro R (2001). Human capital and growth. American Economic Review 91(2): 12-17.

Battese G and Rao D (2002). Technology gap, efficiency, and a stochastic metafrontier function. International Journal of Business 1(2): 87-93.

Battese G, Rao D and O'Donnell C (2004). A metafrontier production function for estimation of technical efficiencies and technology gaps for firms operating under different technologies. Journal of Productivity Analysis 21(1): 91-103.

Bishop JH (1997). The effect of national standards and curriculum-based exams on achievement. The American Economic Review 87(2): 260-264.

Borghans L, Duckworth AL, Heckman JJ and Ter Weel B (2008). The economics and psychology of personality traits. Journal of Human Resources 43(4): 972-1059.

Borghans L and Schils T (2012). The leaning tower of PISA: The effect of test motivation on scores in the international student assessment. Mimeo. http://www.sole-jole.org/13260.pdf, accessed 8 May 2015;

Bradley S, Johnes G and Millington J (2001). The effect of competition on the efficiency of secondary schools in England. European Journal of Operational Research 135(3): 545-568.

Bray M and Thomas RM (1995). Levels of comparison in educational studies: Different insights from different literatures and the value of multilevel analyses. Harvard Educational Review 65(3): 472-490.

Brennan S, Haelermans C and Ruggiero J (2014). Nonparametric estimation of education productivity incorporating nondiscretionary inputs with an application to Dutch schools. European Journal of Operational Research 234(3): 809-818.

Brunello G and Checchi D (2007). Does school tracking affect equality of opportunity? New international evidence. Economic Policy 22(52): 781-861.

Camanho A, Portela MC and Vaz C (2009). Efficiency analysis accounting for non-discretionary factors: The assessment of retailing stores using data envelopment analysis. Computers and Operations Research 36: 1591-1601.
Cazals C, Florens J and Simar L (2002). Nonparametric frontier estimation: A robust approach. Journal of Econometrics 106: 1-25.

Cherchye L, De Witte K, Ooghe E and Nicaise I (2010). Efficiency and equity in private and public education: A nonparametric comparison. European Journal of Operational Research 202(2): 563-573.

Coco G and Lagravinese R (2014). Cronyism and education performance. Economic Modelling 38: 443-450.

Conti G, Heckman JJ and Urzúa S (2011). Early endowments, education and health. Human capital and economic opportunity: A global working group. Working Paper 2011-2001.

Cordero JM, Pedraja F and Santín D (2010). Enhancing the inclusion of non-discretionary inputs in DEA. Journal of Operational Research Society 61(4): 574-584.

Crespo-Cebada E, Pedraja F and Santín D (2014). Does school ownership matter? An unbiased efficiency comparison for regions of Spain. Journal of Productivity Analysis 41(1): 153-172.

Daraio C and Simar L (2005). Introducing environmental variables in nonparametric frontier models: A probabilistic approach. Journal of Productivity Analysis 24(1): 93-121.

Daraio C and Simar L (2007a). Advanced Robust and Nonparametric Methods in Efficiency Analysis. Methodology and Applications. Springer: New York.

Daraio C and Simar L (2007b). Conditional nonparametric frontier models for convex and non convex technologies: A unifying approach. Journal of Productivity Analysis 28(1): 13-32.

De Jorge J and Santín D (2010). Determinantes de la eficiencia educativa en la Unión Europea. Hacienda Publica Española 193(2): 131-155.

Deprins D, Simar L and Tulkens H (1984). Measuring labor inefficiency in post offices. In: Marchand P, Pestieau P and Tulkens H (eds). Concepts and Measurements. Amsterdam: North Holland, pp 243-267.

Deutsch J, Dumas A and Silber J (2013). Estimating an educational production function for five countries of Latin America on the basis of the PISA data. Economics of Education Review 36: 245-262.

De Witte K (2014). Efficiency in education. A review of literature and a way forward. paper presented at Workshop on Efficiency in Education, London.

De Witte K and Kortelainen M (2013). What explains performance of students in a heterogeneous environment? Conditional efficiency estimation with continuous and discrete environmental variables. Applied Economics 45(17): 2401-2412.

De Witte K and Marques R (2009). Capturing the environment, a metafrontier approach to the drinking water sector. International Transactions in Operational Research 16(2): 257-271.

De Witte K and Rogge N (2011). Accounting for exogenous influences in performance evaluations of teachers. Economics of Education Review 30(4): 641-653.

De Witte K, Thanassoulis E, Simpson G, Battisti G and CharlesworthMay A (2010). Assessing pupil and school performance by nonparametric and parametric techniques. Journal of the Operational Research Society 61(8): 1224-1237.

Dronkers J and Robert P (2008). Differences in scholastic achievement of public, private government-dependent, and private independent schools a cross-national analysis. Educational Policy 22(4): 541-577.

Essid H, Ouellette P and Vigeant S (2014). Productivity, efficiency, and technical change of Tunisian schools: A bootstrapped Malmquist approach with quasi-fixed inputs. Omega 42(1): 88-97.

Farrell MJ (1957). The measurement of productive efficiency. Journal of the Royal Statistical Society. Series A 120(3): 253-290.

Foy P and Drucker KT (2013). PIRLS 2011 User Guide for the International Database. TIMSS and PIRLS International Study Center, Boston College: Chestnut Hill, MA.

Fuchs T and Woessmann L (2007). What accounts for international differences in student performance? Empirical Economics 32(2-3): $433-464$. 
Giambona F, Vassallo E and Vassiliadis E (2011). Educational systems efficiency in European Union countries. Studies in Educational Evaluation 37(2): 108-122.

Giménez V, Prior D and Thieme C (2007). Technical efficiency, managerial efficiency and objective-setting in the educational system: An international comparison. Journal of the Operational Research Society 58(8): 996-1007.

Grosskopf S, Hayes KJ and Taylor LL (2014). Efficiency in education: Research and implications. Applied Economic Perspectives and Policy 36(2): 175-210.

Haelermans C and De Witte K (2012). The role of innovations in secondary school performance: Evidence from a conditional efficiency model. European Journal of Operational Research 223(2): 541-549.

Hanushek EA (1979). Conceptual and empirical issues in the estimation of educational production functions. Journal of Human Resources 14(3): 351-388.

Hanushek EA and Kimko DD (2000). Schooling, labor-force quality, and the growth of nations. The American Economic Review 90(5): 1184-1208.

Hanushek EA and Woessmann L (2008). The role of cognitive skills in economic development. Journal of Economic Literature 46(3): 607-668.

Hanushek EA and Woessman L (2011). The economics of international differences in educational achievement. In: Hanushek EA, Machin S and Woessmann L (eds). Handbook of the Economics of Education. Vol. 3. North Holland: Amsterdam, pp 89-200.

Hanushek EA, Link S and Woessmann L (2013). Does school autonomy make sense everywhere? Panel estimates from PISA. Journal of Development Economics 104: 212-232.

Hanushek EA and Woessmann L (2014). Institutional structures of the education system and student achievement: A review of crosscountry economic research. In: Strietholt R, Bos W, Gustafsson JE and Rosen M (eds). Educational Policy Evaluation through International Comparative Assessments. Waxmann Verlag: Münster: pp 145-176.

Haveman R and Wolfe B (1995). The determinants of children's attainments: A review of methods and findings. Journal of Economic Literature: 33(4): 1829-1878.

Heckman JJ (2011). Integrating personality psychology into economics ( $\mathrm{N}^{\mathrm{o}}$ w17378). National Bureau of Economic Research.

Jeong SO, Park BU and Simar L (2010). Nonparametric conditional efficiency measures: Asymptotic properties. Annals of Operations Research 173(1): 105-122.

Jobson JD (ed). (1992). Principal components factors and correspondence analysis. In: Texts in Statistics. Applied Multivariate Data Analysis. Vol. II. Categorical and Multivariate Methods. New York, Springer-Verlag, pp 345-482.

Krueger AB and Lindahl M (2001). Education for growth: Why and for whom. Journal of Economic Literature 39(4): 1101-1136.

Lavy V (2010). Do differences in school's instruction time explain international achievement gaps in Maths, Science and Language? Evidence from developed and developing countries. CEE DP 118. Centre for the Economics of Education (NJ1).

Levin H (1974). Measuring efficiency in educational production. Public Finance Quarterly 2(1): 3-24.

Li Q and Racine JS (2004). Cross-validated local linear nonparametric regression. Statistica Sinica 14(2): 485-512.

Mislevy RJ, Beaton AE, Kaplan B and Sheehan KM (1992). Estimating population characteristics form sparse matrix samples of item responses. Journal of Educational Measurement 29(2): 133-161.

Mullis IVS, Martin MO, Foy P and Drucker KT (2012). PIRLS 2011 International Results in Reading. TIMSS and PIRLS International Study Center, Boston College: Chestnut Hill, MA
O’Donnell C, Rao D and Battese G (2008). Metafrontier frameworks for the study of firm-level efficiencies and technology ratios. Empirical Economics 37(2): 231-255.

Perelman S and Santín D (2011). Measuring educational efficiency at student level with parametric stochastic distance functions: An application to Spanish PISA results. Education Economics 19(1): 29-49.

Racine JS (1997). Consistent significance testing for nonparametric regression. Journal of Business and Economic Statistics 15(3): 369-379.

Racine JS and Li Q (2004). Nonparametric estimation of regression functions with both categorical and continuous data. Journal of Econometrics 119(1): 99-130.

Racine JS, Hart JD and Li Q (2006). Testing the significance of categorical predictor variables in nonparametric regression models. Econometric Reviews 25(4): 523-544.

Rasch G (1960/1980). Probabilistic Models for Some Intelligence and Attainment Tests. Danish Institute for Educational Research: Copenhagen: Expanded edition (1980). The University of Chicago Press.

Rivkin SG and Schiman JC (2013). Instruction time, classroom quality, and academic achievement (No. w19464). National Bureau of Economic Research.

Ruggiero J (1996). On the measurement of technical efficiency in the public sector. European Journal of Operational Research 90(3): $553-565$.

Ruggiero J (2000). Nonparametric estimation of returns to scale in the public sector with an application to the provision of educational services. Journal of the Operational Research Society 51(8): 906-912.

Ruggiero J and Vitaliano DF (1999). Assessing the efficiency of public schools using data envelopment analysis and frontier regression. Contemporary Economic Policy 17(3): 321-331.

Schuetz G, Ursprung HW and Wößmann L (2008). Education policy and equality of opportunity. Kyklos 61(2): 279-308

Silva-Portela MC and Thanassoulis E (2001). Decomposing school and school-type efficiency. European Journal of Operational Research 132(2): 357-373.

Spiezia V (2010). Does computer use increase educational achievements? Student-level evidence from PISA. OECD Journal: Economic Studies 1: 1-22.

Strietholt R, Gustafsson JE, Rosen M and Bos W (2014). Outcomes and causal inference in international comparative assessments. In: Strietholt, R., Bos, W., Gustafsson, J. E., \& Rosén, M. (Eds.) Educational Policy Evaluation through International Comparative Assessments. Waxmann Verlag. Münster, 9-19.

Täht K and Must O (2013). Comparability of educational achievement and learning attitudes across nations. Educational Research and Evaluation 19(1): 19-38.

Thanassoulis E and Silva-Portela A (2002). School outcomes: Sharing the responsibility between pupil and school. Education Economics 10(2): 183-207.

Thieme C, Giménez V and Prior D (2012). A comparative analysis of the efficiency of national education systems. Asia Pacific Education Review 13(1): 1-15.

Thieme C, Prior D and Tortosa-Ausina E (2013). A multilevel decomposition of school performance using robust nonparametric frontier techniques. Economics of Education Review 32: 104-121.

Vandenberghe V and Robin S (2004). Evaluating the effectiveness of private education across countries: A comparison of methods. Labour Economics 11(4): 487-506.

Verhoeven M, Gunnarsson V and Carcillo S (2007). Education and health in G7 countries: Achieving better outcomes with less spending (No. 2007-2263). International Monetary Fund.

Wilder S (2014). Effects of parental involvement on academic achievement: A meta-synthesis. Educational Review 66(3): 377-397. 
Wilson PW (2005). Efficiency in education production among PISA countries, with emphasis on transitioning economies. World Bank Working Paper.

Woessmann L, Luedemann E, Schuetz G and West MR (2009). School Accountability, Autonomy, and Choice Around the World. Edward Elgar: Cheltenham, UK.

Worthington AC (2001). An empirical survey of frontier efficiency measurement techniques in education. Education Economics 9(3): $245-268$.
Wu M and Adams RJ (2002). Plausible Values-Why They are Important. International Objective Measurement Workshop: New Orleans.

Zhao Y, Zhang G, Yang W, Kirkland D, Han X and Zhang J (2008). A comparative study of educational research in China and the United States. Asia Pacific Journal of Education 28(1): 1-17.

Received 11 November 2014; accepted 21 April 2015 after one revision 